\title{
Incidental finding in a young man
}

\author{
Wai Kan Kassel Tsang ${ }^{1} \cdot$ Man Kwong Chan ${ }^{1} \cdot K_{w o k}$ Chung Lai ${ }^{1}$
}

Published online: 6 June 2017

(C) ISS 2017

\section{History:}

Incidental right iliac lesion identified in a 23-year-old male being evaluated for abdominal pain (Figs. 1 and 2).

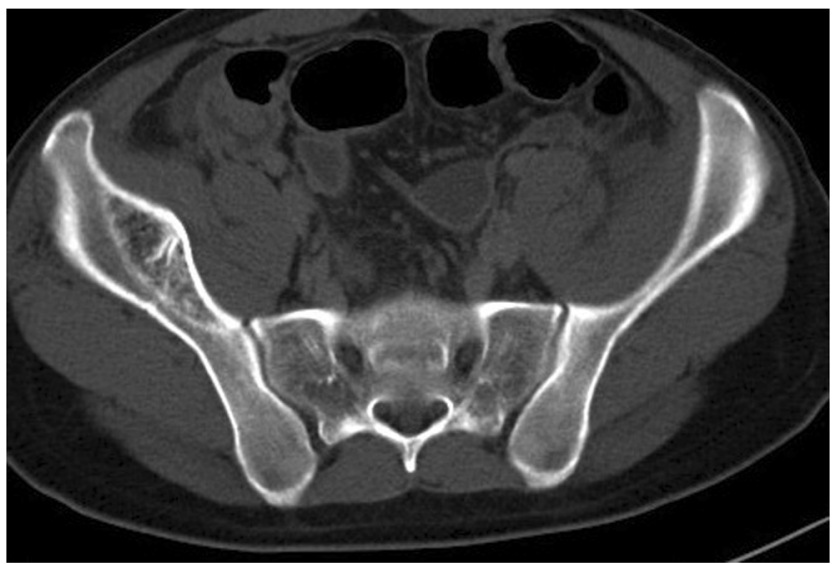

Fig. 1 Axial CT pelvis

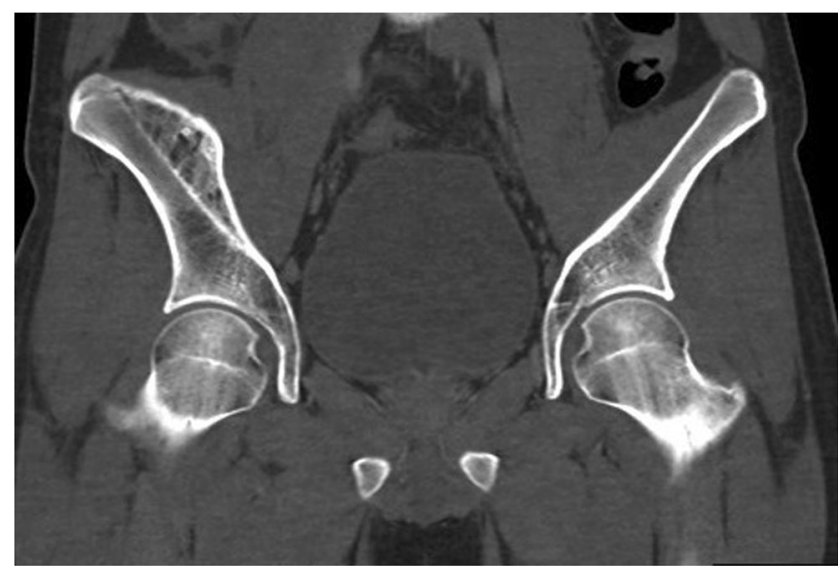

Fig. 2 Coronal CT pelvis

Compliance with ethical standards

Conflict of interest The authors declare that they have no conflict of interest. 